\title{
Informal Caregiving for Persons with Chronic Conditions: Trends and Considerations
}

\author{
Paul B. Arthur \\ Department of Occupational Therapy, St. Catherine University, Minneapolis, MN, USA \\ Email: PBArthur824@StKate.edu
}

How to cite this paper: Arthur, P.B. (2018) Informal Caregiving for Persons with Chronic Conditions: Trends and Considerations. Advances in Aging Research, 7, 78-89.

https://doi.org/10.4236/aar.2018.74007

Received: May 8, 2018

Accepted: July 17, 2018

Published: July 20, 2018

Copyright (C) 2018 by author and Scientific Research Publishing Inc. This work is licensed under the Creative Commons Attribution International License (CC BY 4.0).

http://creativecommons.org/licenses/by/4.0/

\section{(c) (i) Open Access}

\begin{abstract}
Aging adults with chronic conditions rely heavily on an informal network of caregivers to remain within their communities of choice. This reliance can take a significant toll on caregivers through the lens of physical and psychological problems, financial issues, and social isolation. These variables may then lead to less desirable outcomes for care recipients. This review highlights existing support services in their many forms, including: psychosocial interventions, environmental interventions, respite care, and health information technology as a method of delivery. Given the current trend with informal caregivers assuming increased responsibility in healthcare, programs and services supporting these caregivers must be understood and trialed to ensure that their needs are not overlooked.
\end{abstract}

\section{Keywords}

Informal Caregivers, Caregivers, Carers, Support Services, Chronic Conditions, Depression, Burden, Distress

\section{Introduction}

Healthcare systems worldwide are bracing for rapidly aging populations and their many comorbid conditions. In industrialized countries, 25\% of 65 - 69 year olds, and $50 \%$ of $80-84$ year olds are affected by two or more chronic conditions that necessitate formal or informal care [1]. Formal caregivers are generally defined as those being paid for their services; assistance being provided for those either without available family support, or with the financial means (or benefits) to employ such services. Formal caregivers may be found in adult day service organizations, home health arrangements, or in transactional relationships with persons in the community, acquaintance, or family members. Informal caregivers are most often defined as family and/or friends assisting in an unpaid 
transaction of service [2]. In the United States, spouses and eldest daughters most ofen assume this informal caregiving role.

Aging adults with disabilities rely heavily on caregivers to remain within their communities of choice. This reliance may often lead to a challenging situation for caregivers, particularly the informal, through an increase of physical and mental health problems, financial issues, and social isolation [3]. These negative health effects can lead to caregiver stress, depression, and burden, and increase the risk of abuse, as well as increasing the likelihood of institutionalisation of the recipient of care [4] [5].

Caregiver support services may delay nursing home admission. Delayed nursing home admission is associated with individual and societal benefits. Nursing homes are affiliated with a number of troubling outcomes such as questionable quality of care and quality of life, premature mortality, and psychological or emotional distress for families [6] [7]. Additionally, nursing home admission is universally expensive and costs are often carried by public and taxpayer-financed sources when admitted individuals benefits and savings have been exhausted [8] [9].

Informal caregivers are indispensable in addressing the needs of aging adults with disabilities and to prevent an overwhelming takeover of the built healthcare system by a chronic population. For equitable care transactions to occur between caregivers and the aging adults they serve, increased support structures may be required. Support services come in many forms including psychosocial interventions, environmental interventions, respite care, and in interventions implementing health information technology.

\section{Support Services}

\subsection{Psychosocial Interventions}

Psychosocial interventions may target the caregiver, the individual receiving care, or the group (dyad) as one. Regardless of the intervention target, outcome measures tend to reflect both care recipients behaviors (and/or reactions), as well as caregiver responses. Martire et al. [10] conducted a meta-analysis on the benefit of psychosocial interventions for caregivers of persons in multiple illness populations. Seventy randomized controlled trials were reviewed with illness populations including dementia (44.3\%), heart disease (21.4\%), frail older adults (15.7\%), cancer (7.1\%), chronic pain (4.3\%), stroke (2.9\%), rheumatoid arthritis (2.9\%), and traumatic brain injury (1.4\%). Caregiver outcomes of interest included depressive symptoms, anxiety, relationship satisfaction, and caregiving burden.

Notable caregiver results included the reduced depressive symptoms in caregivers of persons with conditions other than dementia in 18 studies $(\mathrm{p}=0.03)$. Additionally, interventions were reported as beneficial for mixed-groups (not exclusively spouse) of family members in 29 studies $(p=0.04)$. Interventions exclusively targeting the caregiver were successful in reducing caregiver depressive 
symptoms in 24 studies $(\mathrm{p}=0.01)$. Family members reported less depression when the intervention included a relationship focus (between caregiver and care recipient) in 22 studies ( $\mathrm{p}=0.01)$. Family burden was decreased in 40 studies ( $\mathrm{p}$ $=0.00$ ), including those performed with caregivers of dementia patients. Family interventions targeting both caregiver and care recipient were successful in reducing caregiver burden in 16 studies $(\mathrm{p}=0.01)$, as were the interventions targeting caregivers exclusively in 24 studies $(\mathrm{p}=0.00)$. Results indicated psychosocial interventions targeting caregivers, care recipients, or both, are generally beneficial, and family interventions may be a promising approach as they provide benefit to the entire unit.

Melis et al. [11] performed a randomized controlled trial on the Geriatric Evaluation and Management (GEM) Program; one performed by general physicians and nurses targeting care recipients cognition, nutrition, behavior, mood, and mobility. One hundred-ten dyads were followed for 6 months. The intervention involved a nurse translating the GEM report from the physician and making specific recommendations to the caregiver. A host of trial recommendations included education about the specific disorder, adult daycare referral, and behavioral suggestions to managing difficult symptoms.

While the program generally benefited the care recipients (frail aging adults), successes were most-often tied to the caregiver living situation, where baseline distress measures were significantly higher for caregivers living with care recepients. Results indicated that psychosocial interventions targeting caregivers and care recipients may perform convincingly better in those cohabiting with the care recipient, than with alternate populations.

Another method of caregiver support through psychosocial intervention is with the provision of group therapy, or support groups. These are generally professional (social worker or similar) or peer organized sessions aimed at building rapport among participants by having discussions regarding caregiving challenges, successes, and feelings [12]. In a meta-analysis aimed at judging effectiveness of such interventions, Sörensen, Pinquart, and Duberstein [12] noted these interventions reduced caregiver burden and increased caregiver ability and knowledge, but did not address depression or care recipient (behavioral) symptoms. Additionally, authors reported that support group interventions generally displayed improved results directly from the targeted intervention introduced (e.g. reducing burden), rather than a host of other alternate factors not directly targeted within the intervention.

With increases in technology, virtual/online support groups have been implemented and tested for caregivers of aging adults with disabilities. One such study, by Marziali, Damianakis, and Donahue [13] tested an internet-based psychotherapeutic support group aimed a mimicking the group interaction with that of a traditional, in-person support group. A number of considerations are necessary when planning interventions involving technology for the aging population. Authors included video conferencing in multiple formats, including 
one-on-one and facilitator-led groups. Results from thematic analysis indicated that online group interactions were capable of duplicating in-person support groups.

Behavioral interventions for aging adults are found most often in dementia literature, as behavioral problems are generally highlighted as the most challenging aspect of caring for persons with Alzheimer's disease [14]. In their randomized controlled trial, Mittelman, Roth, Haley, and Zarit [15] assigned enrollees to either a multicomponent counseling and support intervention or a traditional care attention-control. Caregivers in the intervention group reported lower reaction (negative) scores when compared to the control $(\mathrm{p}=0.0226)$ and the group difference was increasingly marked with longer follow-up intervals, $(p=0.0368)$. Additionally, caregivers in the intervention group had significantly lower appraisals of stressors than controls at the 1-year follow-up $(\mathrm{p}=0.037)$ and continuing through the 4-year follow-up $(\mathrm{p}<0.02)$. Results indicate that despite care recipient behaviors, caregiver reactions and appraisals of stressors can be controlled through a targeted behavioral intervention with lasting impact.

\subsection{Environmental Interventions}

Environmental interventions address a number of chronic health conditions in aging adults. They are perhaps most often implemented to prevent falls in the frail elderly. These interventions are generally effective in reducing the risk of, number of, and mortality associated with falls and can understandably have a positive impact on caregiver measures [16]. Another common environmental intervention involves the removal of barriers to improve aging adult's access and mobility within the home. Starke [17] described a study employing a home modification intervention program in 16 older adults with functional limitations. The intervention included the provision of adaptive equipment and making structural modification (including major remodeling) in the home. The average number of barriers in each home at baseline was 4.7, and after intervention, an average of 2.2 remained. Significant differences were found between pretest and posttest scores of occupational performance $(p=0.0001)$ and for adult satisfaction with performance $(\mathrm{p}=0.0001)$. While results do not reflect caregiver satisfaction, they support the notion that environmental interventions can improve the occupational performance of aging adults with disabilities and could hypothetically decrease caregiver distress, should present environmental barriers be responsible for increase caregiver load. If working with caregivers of persons with dementia, it may be important to consider the individual's stage of dementia when considering environmental modifications, as the goal will not always to be maximizing mobility and home access [18].

Characteristics of the environment are particularly important considerations when caring for persons with dementia. Environmental design has been associated with agitation, aggression, depression, social withdrawal, and psychotic symptoms [19]. Oftentimes a simple, targeted intervention, with consideration 
of environmental design can address concerns of caregivers of persons with dementia.

Gitlin et al. [20] performed a randomized controlled trial of an environmental intervention with caregivers of persons with dementia. Participants were randomized into an intervention including education and physical and social environmental modification provided by an occupational therapist, and a traditional-care control. Caregiver education included instruction on the ability of environment in impacting the care recipient's behaviors. Instruction was provided on how to modify the environment to decrease behavioral disturbances and how to simplify (break-down) tasks.

Results indicated that caregivers reported fewer care recipient declines (than control) in instrumental activities of daily living $(p=0.03)$. Intervention spouses reported reduced upset $(p=0.049)$ and female caregivers reported improved self-efficacy in managing behaviors ( $p=0.038)$. Enhanced self-efficacy in managing care recipients condition was reported in women $(\mathrm{p}=0.049)$ and minorities $(p=0.037)$. Additionally, depressive symptoms were found to be associated with low adherence to the intervention. This is an important finding as caregivers with high depressive symptoms may first need an intervention targeted at their depression, before they can participate in a meaningful trial (environmental or otherwise). Despite this finding, it is evident that simple environmental modification and training can mediate care recipient decline and caregiver burden through reducing caregiver upset and improving self-efficacy.

\subsection{Respite Care}

Respite services generally come in two forms: informally though the lending of time from family members or friends to provide the primary caregiver with a "break", or formally though the employment of health service providers. The caregiver respite experience has been identified as a useful means for temporarily addressing negative physical and social consequences of caregiving [21] and caregivers often identify respite services as their most needed or desired service [22].

Despite the positive aspects of respite, caregivers often find difficulty in seeking, or asking for their needed break. In an attempt to identify how caregivers of persons with dementia experience respite, Strang et al. [21] performed qualitative interviews with caregivers before and after a respite experience. Based on qualitative analysis, authors identified three phases of coping for the respite experience, namely recognition of the need for separation (from care recipient), giving self-permission to separate temporarily, and having appropriate social support resources to separate.

Guilt is highlighted as a significant barrier to quality time away from the care recipient and having a plan for activities to perform while away can improve the respite outcome. Authors suggest that providers should have the ability to recognize the caregivers phase of coping. They will be more-equipped to assist them 
in attaining the correct services when they are needed [21].

There have been few quality randomized controlled trials reported on for respite interventions in the past two decades. Possible reasons for this include the ethical difficulty of controlling for the respite experience (e.g. not allowing a caregiver to have a "break"), as well as unfavorable results in past trials leading to publication bias [23].

Lawton et al. [24] have perhaps completed the most rigorous respite trial, to date, with 632 participants. Caregivers were blind with respect to the respite experience and were generally asked to take part in a caregiving project. The intervention included a 12-month program that included a host of respite options such as home care, daycare, and institutional care. Caregivers determined the type and duration of support received, and received some financial reimbursement to assist with service costs. Controls were not prevented from using respite programming, but they were not guided to do so by the research team.

Ninety-one percent of the participants (intervention and control) reported using some respite services during the period, likely impacting the results. Results indicated no statistically significant differences between the intervention and control groups in the mortality, community status (e.g. institutionalized or not), or caregiver distress. Care recipients with dementia in the intervention group delayed institutionalisation by 22 days $(\mathrm{p}=0.01)$. Caregivers in the intervention group rated themselves as "more relieved" ( $p<0.01)$ and "more satisfied" ( $p<0.05$ ) than those in the control group, though authors suggest the differences between groups may not be clinically significant. Despite the immediate, positive impact of respite services, long term benefits are not well supported in the literature. Generally, respite services have been found to only slightly reduce caregiver strain or improve caregiver morale or satisfaction, and generally only do so while they are active [25].

\subsection{Adult Daycare Services}

Although adult daycare services are sometimes equated to respite care [24] for the sake of this writing, these services will generally be defined as out-of-home programs utilized at least once per week. Zarit et al. [26] performed a quasi-experimental trial with caregivers of persons with dementia. The intervention group utilized adult daycare services 2 or more times a week (minimal) while the control did not use the services at all during the course of the evaluation. Results at 3 months indicated significantly lower scores for the intervention group in caregiver overload ( $p \leq 0.05)$, strain $(p \leq 0.05)$, depression $(p \leq 0.05)$, and anger $(p \leq 0.05)$. At one year, the intervention group maintained significantly lower scores on overload ( $\mathrm{p} \leq 0.05)$ and depression ( $\mathrm{p} \leq 0.05)$. Zarit et al. [26] suggested that caregivers of persons with dementia who utilize adult daycare services experience lower levels of caregiver stress and display better psychological well-being than those who do not.

In another study by Zarit et al. [27] the effects of adult daycare services were 
examined with the daily stressors experienced by caregivers. Results indicated that total exposure to stressors and appraisals of stress decreased significantly over time on daycare days, when compared to non-daycare days (Baseline mean: 121 minutes, 1 month: 75 minutes, 2 months: 52 minutes). It seems most of the differences were accounted for by the time the caregiver spent away from the care recipient. Additionally, results indicated decreased behavioral problems ( $\mathrm{p}$ $<0.001)$ in the care recipient and improved care recipient sleeping patterns ( $\mathrm{p}<$ 0.001 ) on days attending daycare. These studies support the short-term ability of adult daycare services ( 2 days a week or more) to mediate caregiver stress and exposure to stress. Additionally, the studies suggest that by removing the daycare service, symptoms quickly return, implying there is not a long-term effect once removed, as seen in respite care.

\subsection{Health Information Technology}

Although face-to-face interventions and support groups have been implemented and successful for many, caregivers of aging adults with chronic conditions may be unable to leave the home to participate in such interventions, secondary to the nature of the disease. Three of the greatest identified barriers to support group attendance include the lack of available respite or substitute caregiver, transportation difficulties, and inconvenient locations and meeting times [28].

Mahoney, Tarlow, and Jones [29] conducted a randomized controlled study with 100 dyads of caregivers and persons with Alzheimer's disease. The intervention group received a 12-month computer-mediated automated interactive voice response (IVR) intervention aimed at addressing family caregiver burden and anxiety. The control group received of traditional care. The intervention group received one year of access to the IVR system providing stress monitoring, counseling information, accessing to dementia experts via voicemail, a telephone support group, and a distraction-call program for care recipients. Results indicated that the intervention group had the greatest impact on female caregivers possessing high levels of anxiety and low mastery. Significant effects were seen in intervention participants with low mastery in the three outcomes measured, namely "bother" ( $\mathrm{p}=0.04 / \mathrm{p}=0.02$ for wives), "anxiety" ( $\mathrm{p}=0.01)$, and "depression" ( $p=0.02)$. Results indicate that a low-intensity, user-powered technological intervention can be beneficial and impact burden and anxiety of family caregivers of persons with Alzheimer's disease.

Eisdorfer et al. [30] conducted a randomized controlled trial focusing on family therapy for caregivers of persons with Alzheimer's disease. Caregivers were randomized into one of three groups: a Structural Ecosystem Therapy (SET), SET with computer-telephone integrated system (CTIS), or a minimal support control. SET is designed to identify and restructure specific interactions within the family, and between the family and other systems to address caregiver burden. The intent of SET is to identify particular issues the caregiver is having, identify possible support mechanisms, identify the resources available (commu- 
nity and otherwise), and determine the capacity of alternate caregivers to assist with caregiving duties. The CTIS augmented the therapeutic intervention by increasing caregiver and family access to the program therapist. It additionally assisted in the facilitation of contacts for caregiver resources outside of the home for family members to connect with. By design, the also CTIS removed barriers associated with transportation to participate in the SET. Results indicated that caregivers in the combined SET and CTIS reported a significant reduction in depressive symptoms at 6 months (though partially dependent on the race/ethnicity of the caregiver). Symptom increases or subtle changes were found in alternate treatment (SET alone) and minimal-support control arms. An 18-month follow-up showed particularly promising results for Cuban American husband and daughter caregivers, perhaps related to the SET's original design for Hispanic families. Researchers hypothesized that the inclusion of the CTIS may have assisted family caregivers through the provision of additional opportunities for interaction with providers, and generally caregivers had described the system as valuable and generally enjoyed using it to participate in discussion programs.

\section{Discussion}

Support services have been described in many forms including psychosocial interventions, environmental interventions, respite care, and in interventions implementing health information technology. Psychosocial interventions targeting both caregiver and recipient are promising approaches, and the most success is found when the persons are living together. Simple environmental modification and training can compensate for early care recipient decline, aid in self-efficacy, and also lessen caregiver upset. While respite services are treasured by those who quality for and receive them, long term benefits are not well proven, as the response generally deteriorates when the dose (respite) is removed. Similarly, with adult daycare services, favorable outcomes are found when used for 2 days a week or more, though removal of the services is paired with diminished outcomes. Finally, health information technology has been found to be beneficial in group interactions for interventions such as support groups, and can bridge the gap of isolation that may result in secondary to chronic caregiving situations.

While many caregiver support services for those caring for aging adults with chronic conditions have been described, the availability and use of these services are dependent on a number of factors. Service availability, affordability, user-satisfaction, and racial and ethnic variations of utilization are additional points for consideration. Caregiver support services vary widely by region, as does the financial support available [31]. In the United States, rural areas often have the least community resources for support, and economically-disadvantaged states tend to provide less financial aid to persons seeking such. Satisfaction is an important variable of care as it has been positively paired with care utilization, compliance, and results [32]. Naturally, if consumers are not pleased with the level of care they are receiving, they are less likely to continue participation and 
have favorable results. A number of indirect variables have historically been associated with user satisfaction as well, including caregiver relationship, diagnosis, price of care, region, and length of time receiving care [33]. Affordability of support services can be of concern for many caregivers. This is particularly true in the Latino (non-White/Hispanic) communities [34]. Despite similarly-demanding caregiving situations and caregiver strain, minority populations tend to use formal support services must less than White/non-Hispanic peers [35]. Additionally, immigrant populations often find eligibility and service criteria confusing and intimidating, preventing the delivery of service [36].

Continued increases in the aging population necessitate a broad public understanding of caregiver support services. With aging adults receiving the vast majority of assistance from informal caregivers, the needs of individuals assuming this role must not be overlooked in the general plan of care. While a number of caregiver interventions: psychosocial, environmental, respite, and health information technology have been implemented and tested, future studies are warranted to trial interventions with the larger and more general population of caregivers of persons with disabilities.

\section{Conclusion}

Informal networks of caregivers are providing an extraordinary service to the rapidly aging population with chronic conditions in the United States and abroad. The acceptance and assumption of these roles are not without consequence and often carry associated physical, psychological, and financial implications. Given the current healthcare trend in shifting patient care to families and informal caregivers, interventions must be trialed on the populations for which they are best suited to protect the priceless informal caregiver network societies who depend it.

\section{Acknowledgements}

This paper was developed, in part, from the author's doctoral qualification exam. Acknowledgements include his doctoral dissertation committee members: Dr. William C. Mann, Dr. John Kairalla, Dr. Mary Ellen Young, Dr. Orit Shechtman, and Dr. Jamie Pomeranz.

\section{References}

[1] Lopez-Hartmann, M., Wens, J., Verhoeven, V. and Remmen, R. (2012) The Effect of Caregiver Support Interventions for Informal Caregivers of Community-Dwelling Frail Elderly: A Systematic Review. International Journal of Integrated Care, 12, e133. https://doi.org/10.5334/ijic.845

[2] Lyons, K.S. and Zarit, S.H. (1999) Formal and Informal Support: The Great Divide. International Journal of Geriatric Psychiatry, 14, 183-192. https://doi.org/10.1002/(SICI)1099-1166(199903)14:3<183::AID-GPS969>3.0.CO;2-J

[3] Schulz, R. and Sherwood, P.R. (2008) Physical and Mental Health Effects of Family Caregiving. Journal of Social Work Education, 44, 105-113. 
https://doi.org/10.5175/JSWE.2008.773247702

[4] Okamoto, K., Hasebe, Y. and Harasawa, Y. (2007) Caregiver Psychological Characteristics Predict Discontinuation of Care for disabled Elderly at Home. International Journal of Geriatric Psychiatry, 22, 1110-1114. https://doi.org/10.1002/gps.1796

[5] Coyne, A.C., Reichman, W.E. and Berbig, L.J. (1993) The Relationship between Dementia And Elder Abuse. The American Journal of Psychiatry, 150, 643-646. https://doi.org/10.1176/ajp.150.4.643

[6] Gaugler, J.E., Duval, S., Anderson, K.A. and Kane, R.L. (2007) Predicting Nursing Home Admission in the US: A Meta-Analysis. BMC Geriatrics, 7, 13.

https://doi.org/10.1186/1471-2318-7-13

[7] Kane, R.A. (2001) Long-Term Care and a Good Quality of Life Bringing Them Closer Together. The Gerontologist, 41, 293-304.

https://doi.org/10.1093/geront/41.3.293

[8] Mor, V., Intrator, O., Feng, Z. and Grabowski, D.C. (2010) The Revolving Door of Rehospitalization from Skilled Nursing Facilities. Health Affairs, 29, 57-64. https://doi.org/10.1377/hlthaff.2009.0629

[9] Stuck, A.E., Egger, M., Hammer, A., Minder, C.E. and Beck, J.C. (2002) Home Visits to Prevent Nursing Home Admission and Functional Decline in Elderly People. JAMA: The Journal of the American Medical Association, 287, 1022-1028. https://doi.org/10.1001/jama.287.8.1022

[10] Martire, L.M., Lustig, A.P., Schulz, R., Miller, G.E. and Helgeson, V.S. (2004) Is It Beneficial to Involve a Family Member? A Meta-Analysis of Psychosocial Interventions for Chronic Illness. Health Psychology, 23, 599-611. https://doi.org/10.1037/0278-6133.23.6.599

[11] Melis, R.J., van Eijken, M.I., van Achterberg, T., Teerenstra, S., Vernooij-Dassen, M.J., van de Lisdonk, E.H. and Rikkert, M.G.O. (2009) The Effect on Caregiver Burden of a Problem-Based Home Visiting Programme for Frail Older People. Age and Ageing, 38, 542-547. https://doi.org/10.1093/ageing/afp101

[12] Sörensen, S., Pinquart, M. and Duberstein, P. (2002) How Effective Are Interventions with Caregivers? An Updated Meta-Analysis. The Gerontologist, 42, 356-372. https://doi.org/10.1093/geront/42.3.356

[13] Marziali, E., Damianakis, T. and Donahue, P. (2006) Internet-Based Clinical Services: Virtual Support Groups for Family Caregivers. Journal of Technology in Human Services, 24, 39-54. https://doi.org/10.1300/J017v24n02_03

[14] Savva, G.M., Zaccai, J., Matthews, F.E., Davidson, J.E., McKeith, I. and Brayne, C. (2009) Prevalence, Correlates and Course of Behavioural and Psychological Symptoms of Dementia in the Population. The British Journal of Psychiatry, 194, 212-219. https://doi.org/10.1192/bjp.bp.108.049619

[15] Mittelman, M.S., Roth, D.L., Haley, W.E. and Zarit, S.H. (2004) Effects of a Caregiver Intervention on Negative Caregiver Appraisals of Behavior Problems in $\mathrm{Pa}$ tients with Alzheimer's Disease: Results of a Randomized Trial. The Journals of Gerontology Series B: Psychological Sciences and Social Sciences, 59, P27-P34. https://doi.org/10.1093/geronb/59.1.P27

[16] Chang, J.T., Morton, S.C., Rubenstein, L.Z., Mojica, W.A., Maglione, M., Suttorp, M.J. and Shekelle, P.G. (2004) Interventions for the Prevention of Falls in Older Adults: Systematic Review and Meta-Analysis of Randomised Clinical Trials. BMJ: British Medical Journal, 328, 680. https://doi.org/10.1136/bmj.328.7441.680

[17] Stark, S. (2008) Removing Environmental Barriers in the Homes of Older Adults with Disabilities Improves Occupational Performance. OTJR Occupational Therapy 
Journal of Research: Occupation, Participation, and Health, 24, 32-40.

[18] Cheney, P. (2011) The Dementia Dilemma: Strategies for Home Care Treatment. Home \& Community Health Special Interest Section Quarterly, 18, 1-4.

[19] Zeisel, J., Silverstein, N.M., Hyde, J., Levkoff, S., Lawton, M.P. and Holmes, W. (2003) Environmental Correlates to Behavioral Health Outcomes in Alzheimer's Special Care Units. The Gerontologist, 43, 697-711. https://doi.org/10.1093/geront/43.5.697

[20] Gitlin, L.N., Corcoran, M., Winter, L., Boyce, A. and Hauck, W.W. (2001) A Randomized, Controlled Trial of a Home Environmental Intervention: Effect on Efficacy and Upset in Caregivers and on Daily Function of Persons with Dementia. The Gerontologist, 41, 4-14. https://doi.org/10.1093/geront/41.1.4

[21] Strang, V.R., Haughey, M., Gerdner, L.A. and Teel, C.S. (1999) Respite-A Coping Strategy for Family Caregivers. Western Journal of Nursing Research, 21, 450-466.

[22] Shope, J., Holmes, S., Sharpe, P., Goodman, C. and Izenson, S. (1993) Services for Persons with Dementia and Their Families: A Survey of Information and Referral Agencies in Michigan. The Gerontologist, 33, 529-533.

https://doi.org/10.1093/geront/33.4.529

[23] Lee, H. and Cameron, M. (2004) Cochrane Database of Systematic Reviews. John Wiley \& Sons, Oxford.

[24] Lawton, M.P., Brody, E.M. and Saperstein, A.R. (1989) A Controlled Study of Respite Service for Caregivers of Alzheimer's Patients. The Gerontologist, 29, 8-16. https://doi.org/10.1093/geront/29.1.8

[25] Chappell, N.L., Reid, R.C. and Dow, E. (2001) Respite Reconsidered: A Typology of Meanings Based on the Caregiver's Point of View. Journal of Aging Studies, 15, 201-216. https://doi.org/10.1016/S0890-4065(00)00026-8

[26] Zarit, S.H., Stephens, M.A.P., Townsend, A. and Greene, R. (1998) Stress Reduction for Family Caregivers: Effects of Adult Day Care Use. The Journals of Gerontology Series B: Psychological, Sciences and Social Sciences, 53B, S267-S277. https://doi.org/10.1093/geronb/53B.5.S267

[27] Zarit, S.H., Kim, K., Femia, E.E., Almeida, D.M., Savla, J. and Molenaar, P.C. (2011) Effects of Adult Day Care on Daily Stress of Caregivers: A Within-Person Approach. The Journals of Gerontology Series B: Psychological, Sciences and Social Sciences, 66B, 538-546. https://doi.org/10.1093/geronb/gbr030

[28] Gonyea, J.G. (1989) Alzheimer's Disease Support Groups: An Analysis of Their Structure, Format, and Perceived Benefits. Social Work Health Care, 14, 61-72. https://doi.org/10.1300/J010v14n01_05

[29] Mahoney, D., Tarlow, B. and Jones, R. (2003) Effects of an Automated Telephone Support System on Caregiver Burden and Anxiety: Findings from the REACH for TLC Intervention Study. The Gerontologist, 43, 556-567. https://doi.org/10.1093/geront/43.4.556

[30] Eisdorfer, C., Czaja, S.J., Loewenstein, D.A., Rubert, M.P., Argüelles, S., Mitrani, V.B. and Szapocznik, J. (2003) The Effect of a Family Therapy and Technology-Based Intervention on Caregiver Depression. The Gerontologist, 43, 521-531. https://doi.org/10.1093/geront/43.4.521

[31] Hong, M. and Casado, B.L. (2015) Caregiver Stress: Does States' Expenditure on Home- and Community-Based Services Matter? Home Health Care Services Quarterly, 34, 85-100. https://doi.org/10.1080/01621424.2015.1029186

[32] Wellwood, I., Dennis, M. and Warlow, C. (1995) Patients' and Carers' Satisfaction 
with Acute Stroke Management. Age and Ageing, 24, 519-524.

https://doi.org/10.1093/ageing/24.6.519

[33] Meyers, J.L. and Gray, L.N. (2001) The Relationships between Family Primary Caregiver Characteristics and Satisfaction with Hospice Care, Quality of Life, and Burden. Oncology Nursing Forum, 28, 73-82.

[34] Scharlach, A.E., Kellam, R., Ong, N., Baskin, A., Goldstein, C. and Fox, P.J. (2006) Cultural Attitudes and Caregiver Service Use: Lessons from Focus Groups with Racially and Ethnically Diverse Family Caregivers. Journal of Gerontological Social Work, 47, 133-156. https://doi.org/10.1300/J083v47n01_09

[35] Dilworth-Anderson, P., Williams, I. and Gibson, B. (2002) Issues of Race, Ethnicity, and Culture in Caregiving Research: A 20-Year Review (1980-2000). The Gerontologist, 42, 237-272. https://doi.org/10.1093/geront/42.2.237

[36] Pang, E.C., Jordan-Marsh, M., Silverstein, M. and Cody, M. (2003) Health-Seeking Behaviors of Elderly Chinese Americans: Shifts in Expectations. The Gerontologist, 43, 864-874. https://doi.org/10.1093/geront/43.6.864 